\title{
A Conceptual Framework for the Spruce Budworm Early Intervention Strategy: Can Outbreaks be Stopped?
}

\author{
Robert C. Johns ${ }^{1, *}$, Joseph J. Bowden ${ }^{2}{ }^{(D}$, Drew R. Carleton ${ }^{3}$, Barry J. Cooke ${ }^{4}$, Sara Edwards ${ }^{5}$, \\ Erik J. S. Emilson ${ }^{4}$, Patrick M. A. James ${ }^{6}$, Dan Kneeshaw ${ }^{7}$, David A. MacLean ${ }^{8}$ (D, \\ Véronique Martel ${ }^{9}$, Eric R. D. Moise ${ }^{2} \mathbb{D}$, Gordon D. Mott ${ }^{10}$, Chris J. Norfolk ${ }^{3}$, Emily Owens ${ }^{1}$, \\ Deepa S. Pureswaran ${ }^{9}$, Dan T. Quiring ${ }^{11}$, Jacques Régnière ${ }^{9}$, Brigitte Richard ${ }^{12}$ \\ and Michael Stastny ${ }^{1}$ \\ 1 Natural Resources Canada, Canadian Forest Service, Atlantic Forestry Centre, Fredericton, NB E3B 5P7, \\ Canada; emily.owens@canada.ca (E.O.); michael.stastny@canada.ca (M.S.) \\ 2 Natural Resources Canada, Canadian Forest Service, Atlantic Forestry Centre, Corner Brook, NL A2H 5G4, \\ Canada; joseph.bowden@canada.ca (J.J.B.); eric.moise@canada.ca (E.R.D.M.) \\ 3 New Brunswick Department of Energy and Resource Development, 1350 Regent Street, Fredericton, \\ NB E3C 2G6, Canada; drew.carleton@gnb.ca (D.R.C.); chris.norfolk@gnb.ca (C.J.N.) \\ 4 Natural Resources Canada, Canadian Forest Service, Great Lakes Forestry Centre, Sault Ste. Marie, \\ ON P6A 2E5, Canada; barry.cooke@canada.ca (B.J.C.); erik.emilson@canada.ca (E.J.S.E.) \\ 5 Forest Protection Ltd., 2502 Route 102 Highway, Lincoln, NB E3B 7E6, Canada; sara.edwards@unb.ca \\ 6 Faculty of Forestry, University of Toronto, Toronto, ON M5S 3E8, Canada; patrick.james@utoronto.ca \\ 7 Université de Montréal, Département des Sciences Biologiques, Pavillon Marie-Victorin, C.P. 6128, \\ Succursale Centre-Ville Montréal, QC H3C 3J7, Canada; kneeshaw.daniel@uqam.ca \\ 8 Faculty of Forestry and Environmental Management, University of New Brunswick, Fredericton, \\ NB E3B 5A3, Canada; macleand@unb.ca \\ 9 Natural Resources Canada, Canadian Forest Service, Laurentian Forestry Centre, Québec City, QC G1V 4C7, \\ Canada; veronique.martel@canada.ca (V.M.); deepa.pureswaran@canada.ca (D.S.P.); \\ jacques.regniere@canada.ca (J.R.) \\ 10 U.S. Forest Service (retired), 42 Damon Pasture Lane, Lakeville, ME 04487, USA; forester@AlmanacMtn.US \\ 11 Population Ecology Group, Faculty of Forestry and Environmental Management, University of New Brunswick, \\ Fredericton, NB E3B 6C2, Canada; dquiring@mac.com \\ 12 Natural Resources Canada, Communications and Portfolio Sector, Atlantic Forestry Centre, Fredericton, \\ NB E3B 5P7, Canada; Brigitte.richard2@canada.ca \\ * Correspondence: rob.johns@canada.ca; Tel.: +1-506-260-5457
}

Received: 13 August 2019; Accepted: 10 October 2019; Published: 16 October 2019

\begin{abstract}
The spruce budworm, Choristoneura fumiferana, Clem., is the most significant defoliating pest of boreal balsam fir (Abies balsamea (L.) Mill.) and spruce (Picea sp.) in North America. Historically, spruce budworm outbreaks have been managed via a reactive, foliage protection approach focused on keeping trees alive rather than stopping the outbreak. However, recent theoretical and technical advances have renewed interest in proactive population control to reduce outbreak spread and magnitude, i.e., the Early Intervention Strategy (EIS). In essence, EIS is an area-wide management program premised on detecting and controlling rising spruce budworm populations (hotspots) along the leading edge of an outbreak. In this article, we lay out the conceptual framework for EIS, including all of the core components needed for such a program to be viable. We outline the competing hypotheses of spruce budworm population dynamics and discuss their implications for how we manage outbreaks. We also discuss the practical needs for such a program to be successful (e.g., hotspot monitoring, population control, and cost-benefit analyses), as well as the importance of proactive communications with stakeholders.
\end{abstract}


Keywords: foliage protection; population control; monitoring; area-wide management; science communication; economic and ecological cost: benefit analyses

\section{Introduction}

Ecological disturbances such as forest fires and insect outbreaks play a crucial role in shaping productivity, structure, and successional dynamics of forest ecosystems [1]. Despite these essential functions, disturbances sometimes reach levels that harm local ecosystems or socioeconomic interests, thus justifying human intervention [2]. Where outright prevention is impossible or impractical, intervention efforts tend to track one of two strategic pathways. One strategy is to manage the disturbance proactively, deploying large-scale suppression efforts to stop the disturbance before it spreads. The alternative reactive strategy is to let the disturbance run its natural course while only protecting the most valuable resources in its path. For managing insect pests, we often refer to these proactive and reactive strategies, respectively, as 'population control' and 'plant protection' [3]. Both strategies can be useful in pest management but require very different conceptual frameworks, action criteria and thresholds, as well as cost-benefit trade-offs that ultimately determine their relative suitability, feasibility, and efficacy.

Historically, pest management programs for forest insects have favored reactive plant protection over proactive population control. This is certainly the case for the spruce budworm, Choristoneura fumiferana Clem., the foremost defoliating pest of balsam fir (Abies balsamea (L.) Mill.) and spruce (Picea sp.) throughout the North American boreal and eastern mixedwood forest [2]. The plant protection strategy (aka, Foliage Protection strategy) for managing spruce budworm first came to prominence nearly 70 years ago and arose in part as a response to failed attempts at population control. During the early 1950s, researchers leading the first large-scale efforts to manage spruce budworm were optimistic that aggressive use of DDT (dichlorodiphenyltrichloroethane), a powerful broad-spectrum insecticide, could reduce populations to pre-outbreak levels [4,5]. This conviction was tested in 1952 with the aerial application of DDT to over 186,000 ha of budworm-infested forest in northern New Brunswick, Canada at an application rate of $\sim 0.45 \mathrm{~kg} / \mathrm{ha}[4,5]$. Despite inflicting substantial larval mortality, as high as $99 \%$ in some stands, the outbreak continued to expand and populations quickly rebounded in treated areas [4,6]. Almost immediately, researchers abandoned large-scale population control efforts and recalibrated operations for more localized, fine-scale Foliage Protection [5]. In making this shift, they scaled back DDT application rates to merely limit defoliation and thereby prevent tree death. Over time other broad-spectrum insecticides were adopted (e.g., fenitrothion, matacil) to address the significant environmental concerns around the use of DDT and to reduce the probability of selection for insecticide resistance [7]. These broad-spectrum, topical insecticides were eventually banned entirely and replaced with new types of ingestible insecticides that specifically targeted larval Lepidopterans (Bacillus thuringiensis var. kurstaki (Btk) and tebufenozide) [8-10]. Protection efforts were limited mainly to high-value spruce-fir stands with more than two years of moderate defoliation and high budworm densities [5,11]. In eastern Canada, Foliage Protection has remained the dominant management strategy for spruce budworm for the better part of three outbreaks since the 1950s, including for the current outbreak in eastern Québec [12].

In recent decades, substantial advances in population theory and experimentation, insecticide specificity, as well as surveillance and treatment technologies have provided researchers with renewed opportunity to test proactive population control strategies $[3,13]$. In this article, we explore the conceptual basis for developing a proactive population control strategy for spruce budworm, the so-called Early Intervention Strategy (EIS). The EIS aims to stop the expansion of spruce budworm outbreaks by controlling emerging 'hotspots' as soon as they arise. This approach is informed by the success of area-wide management programs for invasive pest species, such as the gypsy moth [14], and draws on ecological theories behind vertebrate population management (e.g., [15,16]). 
Development and testing of EIS has been ongoing in the eastern Canadian province of New Brunswick since 2014 and so far appears to be effective for containing outbreak spread [13]. To our knowledge, this program constitutes the first ever attempt to develop an outbreak containment program for an endemic forest insect pest.

Here, we lay out the conceptual framework for our novel EIS approach and its essential components. First, we describe the underlying population dynamics that might make spruce budworm amenable to population control. We then outline the practical components needed for such a program to succeed (i.e., hotspot monitoring, population control, cost-benefit analyses, and public engagement). This EIS framework provides the basis for guiding effective management, including methods to evaluate EIS efficacy, determining under what conditions it might work best, and identifying knowledge and technical gaps for future research.

\section{Conceptual Framework}

\subsection{Population Dynamics}

Effective population management requires an understanding of how outbreaks start (Figure 1). For spruce budworm, the initiation of outbreaks has been a topic of debate largely centered on two competing theories, the 'oscillatory hypothesis' and the 'double-equilibrium hypothesis' ([3], Table S1). Several recent reviews have synthesized the historical and theoretical details of these hypotheses [2,3], so here we will highlight some of the core arguments and their implications for managing spruce budworm outbreaks.

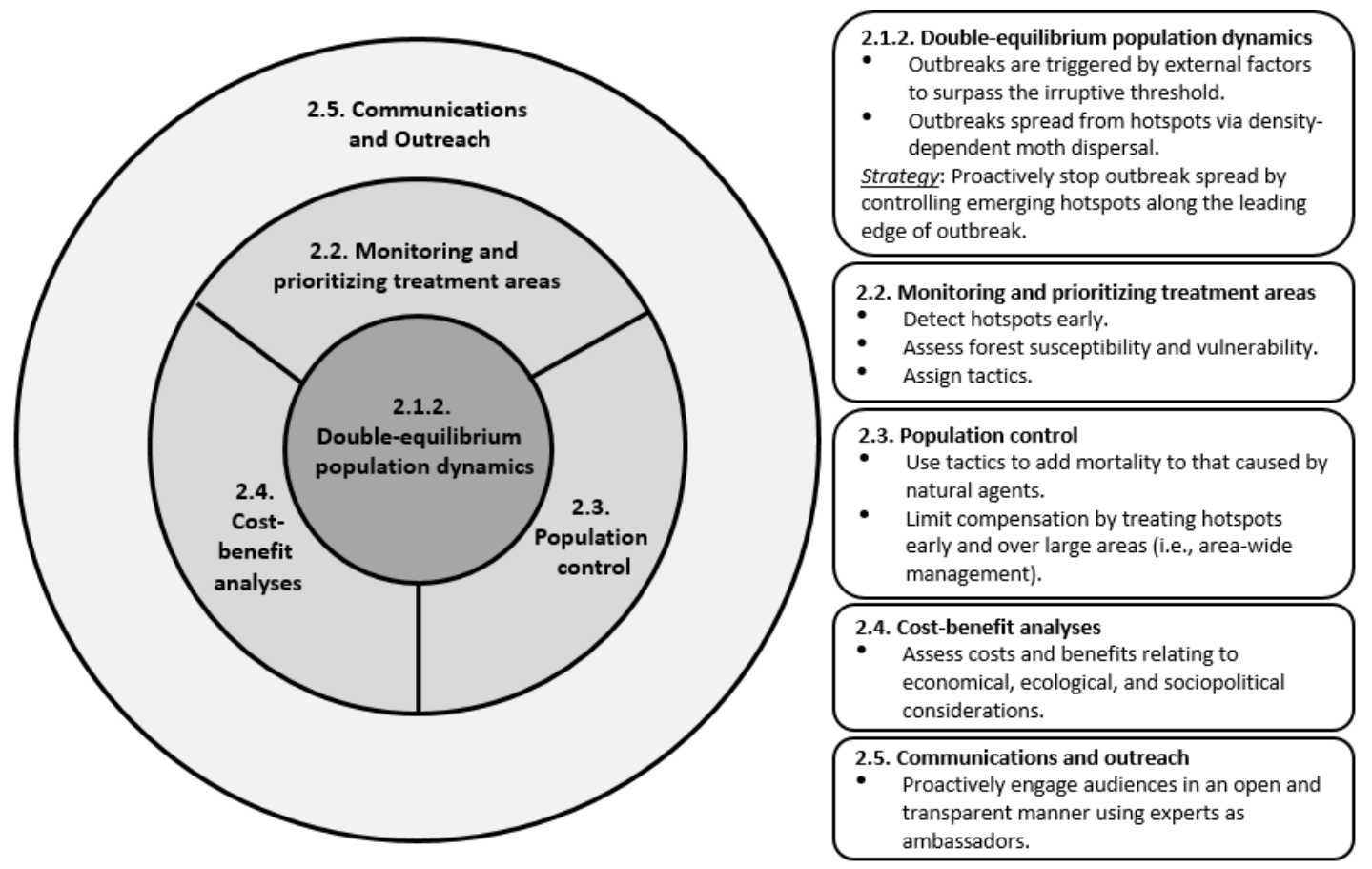

Figure 1. A conceptual framework for Spruce budworm Early Intervention Strategy (EIS) program illustrating the relationships between its different components. Double-equilibrium population dynamics provides the core ecological justification for EIS. In turn, the aims of EIS dictate monitoring and treatment prioritization protocol, population control practices and tactics, and the criteria used in cost-benefit analyses. These particular components are highly dependent upon one another, in that challenges or innovations in one component will likely influence the efficacy or feasibility of the others. Proactive communications and outreach are essential for disseminating information and garnering social license to allow all other aspects of the program to operate. Numbers denote the section of each topic within the body of the article. 


\subsubsection{Oscillatory Dynamics}

Certainty around the inevitability of outbreaks was bolstered in the 1980s by the development of the so-called oscillatory hypothesis (Table S1). In brief, Royama [17,18] argued that budworm outbreaks are part of a slow, cyclical oscillation of density-dependent mortality in late-instar larval and pupal stages shaped by predators, parasitoids, and disease. Outbreaks arise only after spruce budworm become so scarce that natural enemy populations collapse. As mortality rates decline, spruce budworm populations grow rapidly, and in some instances reach densities that strip trees of all new foliage. But, as spruce budworm populations grow so does natural enemy abundance, albeit with a lag of a few years. The resurgence of natural enemies and diseases drive budworm populations back to low density, and the cycle begins anew.

A core tenet of the oscillatory hypothesis is that the cycles occur over relatively large areas, with disparate pockets rising more or less synchronously across the region [19-21]. Moth dispersal, although frequent and often conspicuous during outbreaks [22-24], does not drive outbreak spread per se but rather acts in tandem with weather to draw regional outbreak trends into closer synchrony [20,25]. According to the oscillatory hypothesis, moth dispersal does not start outbreaks, but can hasten or slow population growth and create "noise" in an otherwise smooth predator-prey cycle.

These arguments provide the justification for Foliage Protection. If this oscillatory dynamic is ubiquitous throughout spruce budworm's range, range-wide outbreaks are essentially inevitable. Population control efforts (including EIS) against rising populations would be futile as inherently high growth rates and strong regional synchronization of outbreaks would perpetually swamp control efforts and quickly return treated sites to outbreak levels. Instead, a reactive Foliage Protection strategy becomes the obvious solution to reduce the multi-year cumulative defoliation that leads to tree mortality.

\subsubsection{Double-Equilibrium Dynamics and EIS}

It is worth emphasizing that the oscillatory explanation for how and why outbreaks start did not arise from field data. When it was conceptualized in the early 1980s, detailed life table data for spruce budworm were only available for peak and declining outbreak stages [3]. Recent studies have sought to fill this knowledge gap, which has led to skepticism around the 'inevitability' of regional spruce budworm outbreaks. Our current understanding of outbreak dynamics more strongly supports an updated version of an older idea, the so-called double-equilibrium hypothesis [26-28] (see also Table S1).

In essence, the double-equilibrium hypothesis argues that spruce budworm outbreak dynamics are driven by irruptive population shifts between lower and upper equilibrium states. At the lower (endemic) equilibrium, populations remain low due to heavy mortality caused by natural enemies [29], poor larval dispersal success, inclement weather events, and reduced mating success among females (i.e., "Allee effects" or "depensation" [30]). Outbreaks occur when mortality rates decline or recruitment increases, thus triggering rapid population growth that may eventually approach the local carrying capacity. At this stage, populations enter the upper (epidemic) equilibrium and persist there until natural enemies and diseases, acting alone or synergistically with declining foliage availability, drive populations back to low density [31]. Thus, outbreaks are not the product of simple predator-prey cycles, but instead follow more of an irruption-collapse dynamic with populations fluctuating between two density extremes.

A key implication of the double-equilibrium hypothesis is that moth dispersal does not merely synchronize population growth-it is also an active driver of outbreak spread. Outbreaks may start in small, localized patches (aka hotspots), perhaps "spontaneously" from enhanced survival in response to local factors (e.g., [28]), but these rapidly rise and begin to emit moths into neighboring forests in a density-dependent fashion [24]. This outflow of moths triggers rapid population rise such that growth quickly outstrips the capacity of local mortality agents to keep populations low. These new hotspots become sources of moths leading to explosive propagation of the epidemic, which continues until 
resources collapse and/or natural agents can regain control. This dynamic implies that in the absence of significant moth dispersal, outbreaks would remain relatively geographically isolated.

This interpretation of spruce budworm dynamics has several important implications for population management (Figure 2). Ideally, if we could predict or detect an outbreak early, we could use an EIS program to proactively control hotspots at their origin, thus preventing a regional outbreak. Alternatively, if an outbreak has already surpassed levels that might be manageable via population control-as is currently the case in Québec-we might use EIS to control hotspots along the leading outbreak edge as a way to contain further spread or reduce the magnitude of outbreak. This is akin to "slow-the-spread" strategies used with exotic invasive pests [14]. A key underpinning of EIS is the existence of an irruption threshold below which populations tend to be constrained at the lower equilibrium state by natural enemies [29] and a paucity of mates [30] (i.e., depensatory pressures). Depending on how robust and persistent these depensatory pressures are, populations driven below this threshold may remain low or go locally extinct even without further intervention [32]. Recent work by Régnière et al. [28] suggests that this threshold for spruce budworm in relatively pure balsam fir stands lies around four fourth-instar feeding larvae per $45 \mathrm{~cm}$ branch tip, which roughly translates to seven second-instar larvae (L2) per branch. This is likely conservative, as stands with higher hardwood content would have a higher density threshold owing to population dilution and more diverse and robust natural enemy communities [33-36]. Thus, the aim (and challenge) of EIS is to detect local populations as they surpass the irruption threshold (i.e., become hotspots) and cause sufficient mortality to return them to the lower equilibrium state (Figure 2).

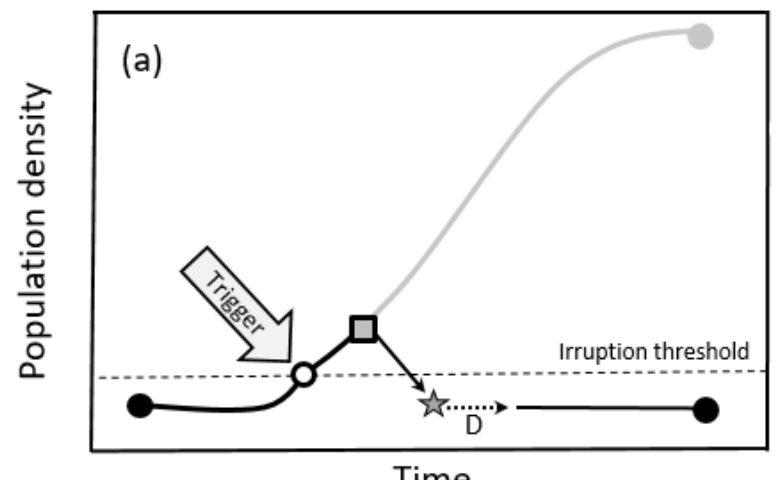

Time

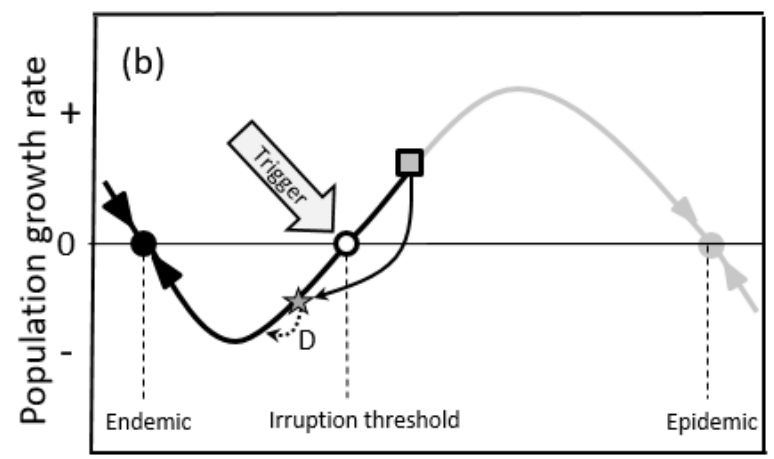

Population density

Figure 2. Hypothetical population trend (a) and recruitment curve (b) for rising spruce budworm populations under the 'double-equilibrium' hypothesis [26,27]. White circles represent the unstable irruption threshold, whereas the filled circles are stable. Gray boxes represent the starting point of a control treatment (e.g., with an insecticide), with its potential impacts on population density or growth rate indicated by stars, followed by expected population responses. Under this dynamic, sufficient treatment mortality (i.e., that is additive to natural mortality) may return populations to the lower equilibrium (dotted lines, grey stars), where depensatory pressure ('D') may keep populations low. 


\subsection{Monitoring and Prioritizing Treatment Areas}

EIS requires efficient methods for detecting hotspots and identifying priority areas for spruce budworm control [13]. Many of the same proxies for population density used in Foliage Protection programs are also used in EIS [37]. However, the sampling intensity and action thresholds used to define treatment areas in EIS differ substantially. The basic protocol for defining treatment priority areas in EIS involves: (1) detecting hotspots; (2) assessing forest susceptibility; and (3) selecting and assigning control tactics.

\subsubsection{Detecting Hotspots}

EIS detects and monitors hotspots through annual sampling of overwintering L2. These data provide the first consideration in prioritizing areas for treatments. L2 monitoring is useful for several reasons. First, L2 density acts as a fair proxy of population density relative to irruption threshold where populations seemingly shift into their outbreak phase [28]. Second, L2 sampling occurs in the fall and winter, which provides sufficient time for budget and treatment planning for the upcoming season. Finally, L2 monitoring has been the convention for monitoring annual budworm densities for Foliage Protection since the early 1980s. As such, the techniques and infrastructure for collecting and extracting larvae from branches are well-established and relatively low cost [37].

Monitoring via L2 densities is much more intensive in EIS than in Foliage Protection as the program requires a much higher spatial resolution to ensure that potential hotspots are not missed [13]. EIS also uses secondary proxies of population density to identify areas of interest for follow-up L2 branch collections, including pheromone trapping of male moths [38] and defoliation assessment via aerial surveys and branch sampling [39]. Instances of abnormally high moth or defoliation levels trigger a second round of L2 sampling in the affected area, which further help to define treatment area boundaries. All areas with known spruce budworm L2 densities above the irruption threshold are set to high priority to ensure their treatment.

L2 monitoring efficiency could be further enhanced in the future through integration with modelling tools to predict moth dispersal patterns via weather forecasting [40] or radar [23], or through defoliation assessment using remote monitoring approaches [41,42].

\subsubsection{Assessing Forest Susceptibility}

Although L2 densities are the basis for interpolating treatment areas, forest composition provides a secondary criterion to optimize insecticide applications. This procedure involves incorporating stand composition into treatment-priority area calculations through differential weighting of stands based on species composition [13].

The relative abundance of mature balsam fir is likely to substantially impact outbreak severity and population growth trends (Figure 3). Stands dominated by balsam fir are particularly susceptible and vulnerable to spruce budworm. During outbreaks balsam fir suffer an average of $\sim 85 \%$ mortality in mature stands and $\sim 40 \%$ mortality in immature stands [43]. In comparison, the other host species-white spruce (Picea glauca (Moench) Voss), red spruce (Picea rubens Sarg.), and black spruce (Picea mariana (Mills.) B.S.P.)—sustain, respectively, $72 \%, 41 \%$, and $28 \%$ as much defoliation as balsam fir [44]. Especially during the early rising phase of the outbreak targeted by the EIS, balsam fir sustains the highest intensity of defoliation even when other hosts are available [45]. 


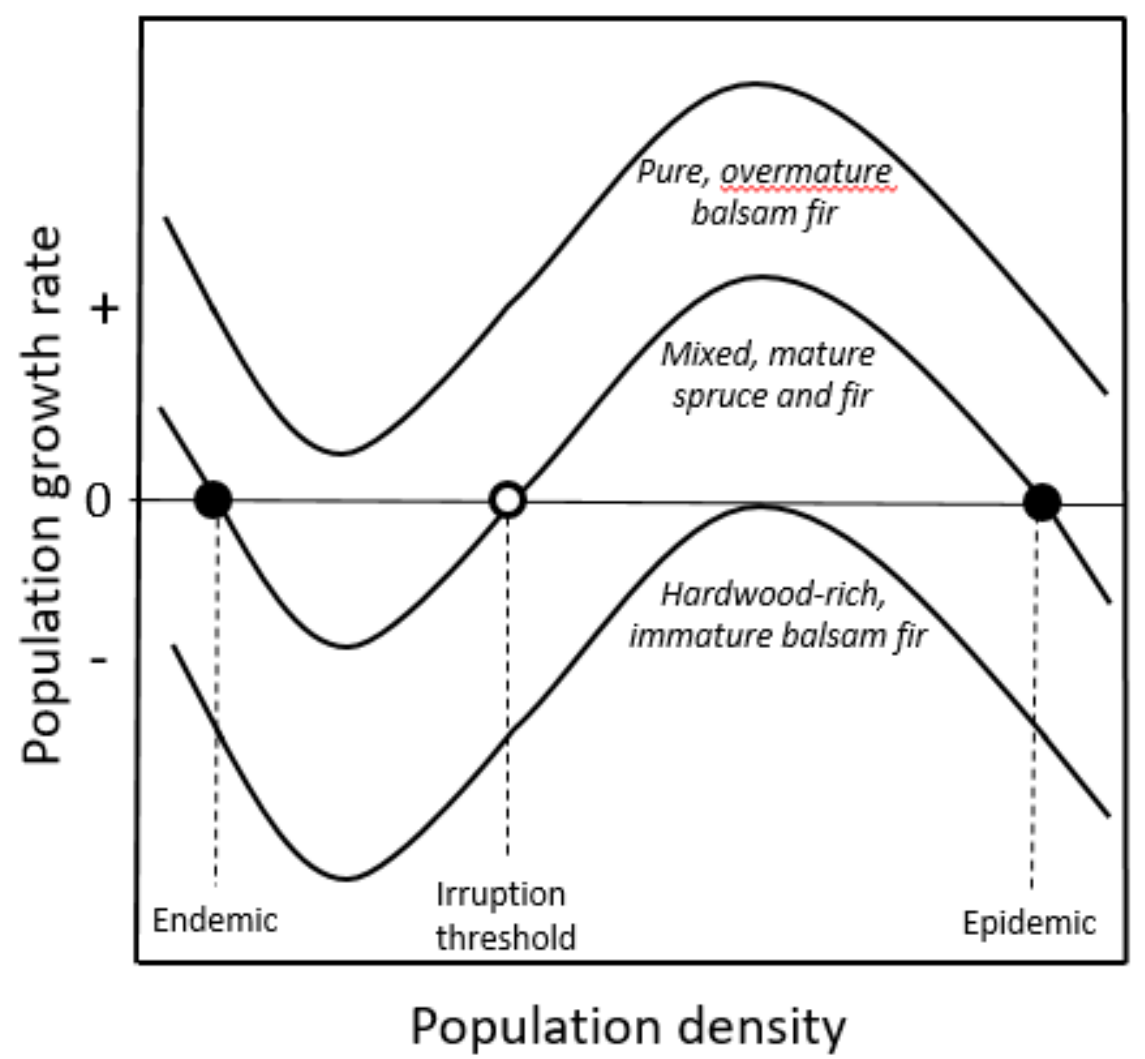

Figure 3. Hypothetical recruitment curves for spruce budworm showing how population density and forest type might interact to influence forest susceptibility and action priorities (adapted from [19]).

Several studies also suggest that during spruce budworm outbreaks, stand-level and landscape-level defoliation and growth loss in balsam fir may decline with increasing proportions of non-host, hardwood species [46-48]. Reduced population growth rates and associated outbreak severity in mixed or hardwood-dominated areas (Figure 3) may reflect increased parasitoid community complexity and pressure [33-36] or increased dispersal mortality during early instars. Zhang et al. [48] also showed, however, that hardwood effects are most evident during the rising phase of an outbreak and become muted as overall defoliation severity increases.

In the current EIS program, spruce-fir and hardwood contents are the only forest composition factors used in refining the treatment priority layer [13]. Future iterations of this process could also incorporate thresholds associated with less susceptible species (e.g., black or red spruce), though these have not been tested to date. Forest landscape structure, including forest configuration and fragmentation, could also be incorporated as they have small but significant effects on outbreak severity $[49,50]$. Additionally, these factors play a role in determining the geographic locations of outbreak development (e.g., hotspots). Recently, Bouchard and Auger [51] demonstrated that outbreaks tended to start in low elevation, high-density host stands. Refined models of forest susceptibility and vulnerability to spruce budworm attack will be essential to fully integrate the influence of forest spatial heterogeneity into the EIS.

\subsubsection{Selecting and Assigning Control Tactics}

After establishing the treatment priority area, the final step is to determine which insecticide to use and where. Two registered insecticides are currently available for spruce budworm in Atlantic Canada: Btk [9] and tebufenozide [10]. Btk is a bacterial agent that upon ingestion by larvae causes the breakdown of the insect's gut wall and ultimately death [52]. Tebufenozide is a synthetic chemical that mimics the juvenile molting hormone. When ingested, tebufenozide triggers premature molting 
or other developmental and reproductive complications during later stages that end in death or sterility [53]. A third registered product, a synthesized spruce budworm pheromone, could disrupt mating but has not yet proven efficacious for population control $[54,55]$. Because Btk and tebufenozide are both applied aerially using the same application technologies, and are similarly efficacious [28], neither product has particular operational advantages over the other. However, tebufenozide has additional label restrictions prohibiting application in designated protected watersheds and residential areas, where Btk is therefore assigned automatically. In all other scenarios, product choice focuses on the logistics required to store both products at multiple bases and flight costs to treatment areas. To date, EIS has tended to use both insecticides in roughly equal measure [13], in part to reduce the likelihood of spruce budworm becoming resistant to either product.

\subsection{Population Control}

EIS does not aim to eradicate spruce budworm from the forest. Nor is population control achieved simply by inflicting maximal mortality in high-density populations, as was assumed during experiments with DDT in the early 1950s [4]. Populations respond in a variety of ways following insecticide treatments and knowing how and why they respond in certain ways is the key to effective population control (Figure 4). In the ideal scenario, EIS is able to impose sufficient additive mortality to reduce populations below the irruption threshold, where depensatory pressures may continue to ensnare the population (e.g., [29,30]; Figure 2). However, there are also management scenarios where treatment mortality is insufficiently additive or where populations compensate, resulting in rebound (Figure 4). Which scenario plays out depends largely on what types of tactics are used and how these tactics are used. Population control programs for invasive organisms offer insights on how to more efficiently enhance additive mortality and minimize compensation [14-16]. These provide the basis for the tactics and practices used in EIS [13].

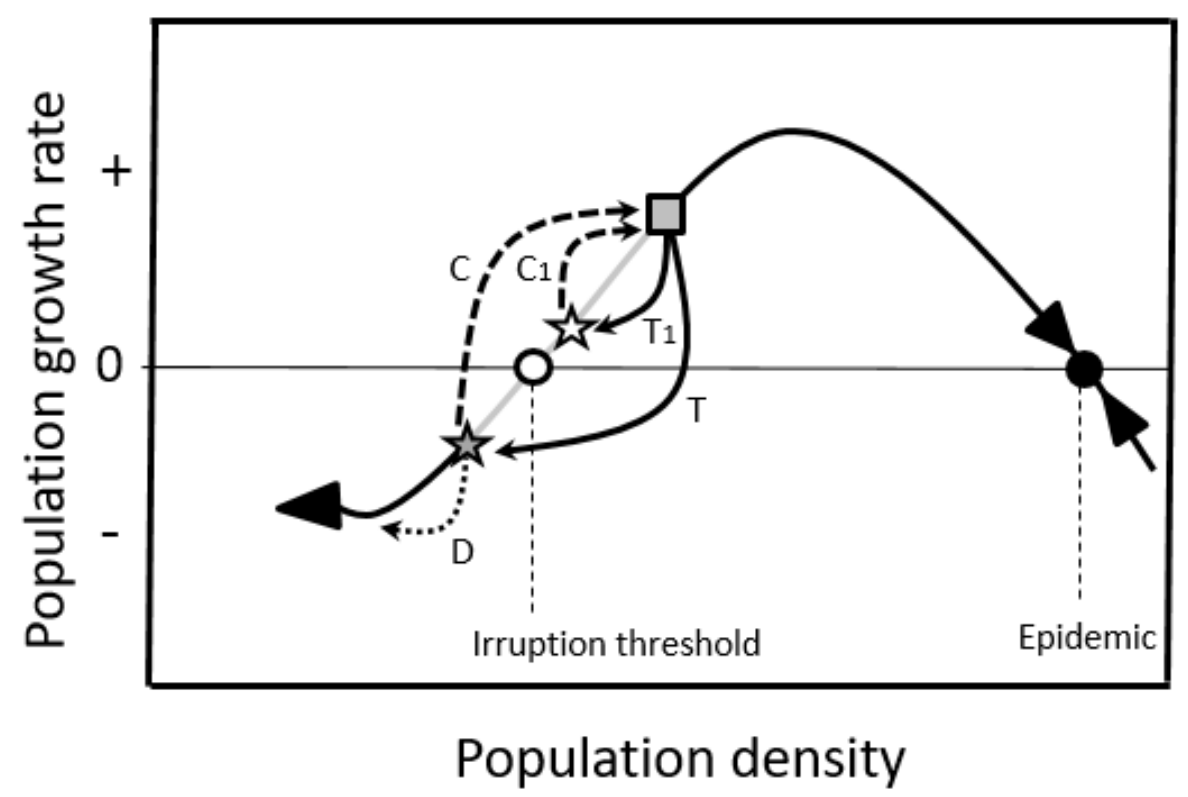

Figure 4. Hypothetical recruitment curve for rising spruce budworm populations with different intensities of treatment mortality and possible population responses. The gray box represents the starting point of a treatment (e.g., with an insecticide) with its potential impacts on population density and growth rate indicated by the stars. Relatively high (and additive) treatment mortality (T) may return populations to the lower equilibrium (gray star) where depensatory pressure (D) should keep populations low in the absence of a strong compensatory response $(\mathrm{C})$. On the other hand, inadequate treatment mortality $\left(T_{1}\right)$ and even modest compensation $\left(C_{1}\right)$ could allow populations to rebound (thick dashed lines) and continue the outbreak. 


\subsubsection{Enhance Additive Mortality}

To reduce populations below the irruption threshold, tactics used in EIS must enhance mortality above that occurring naturally, and this additive mortality must be high enough to reduce populations to below the irruption threshold (Figure 4). In other words, treatment mortality cannot completely overlap or interfere with mortality from natural agents. Because of their particular biological modes of action and the timing of their application, neither Btk nor tebufenozide should directly affect the more than 78 reported parasitoids and entomopathogens, or its myriad vertebrate and invertebrate predators [34,56-58]. Some concerns have been raised that by killing spruce budworm larvae or other species of caterpillars harboring parasitoid larvae there could be indirect effects on parasitoid populations that could reduce natural control in subsequent generations. However, for Btk at least this risk is probably low, as parasitism tends to suppress feeding rates making parasitized larvae less likely to ingest a lethal insecticide dose [59,60]. Indeed, it has been shown that ingestible insecticides sprayed later in the season (i.e., when the feeding rates of parasitized budworm are dropping) can help to minimize redundant mortality [61], thus potentially boosting additive mortality from Btk as well as natural enemy impacts across generations. Whether similar interactions occur for parasitized larvae that have ingested tebufenozide remains unknown.

Development or integration of other tactics that can add mortality while avoiding interference with natural enemies (e.g., tree resistance, biological control, semiochemical control) could further increase EIS efficiency and efficacy [62,63].

\subsubsection{Limit Compensation}

Compensation may occur after treatments if mortality is insufficient to reduce populations below the irruptive threshold (Figure 4). Because of the inherently high reproductive rate of spruce budworm, even a modest proportion of survivors can rapidly replenish a treated area. Adding to this, inflicting mortality on populations that are too far above the outbreak threshold is likely to alleviate density-dependent mortality resulting from competition. Such was the case in the DDT trials of the early 1950s, where severe early-instar larval mortality was offset by enhanced survival and fecundity in later life stages, thus allowing populations to bounce back within just a year or two [6]. This rebound occurred despite high parasitism rates, which in comparison to untreated sites were either unaffected or higher following DDT treatments [6,58]. To counter this aspect of outbreak dynamics in spruce budworm, EIS focuses on controlling hotspots as soon as they arise. Although it is not yet clear what population level is "too high" for EIS, there does appear to be a threshold at around $28 \%$ defoliation (or $~ 10$ fourth-instar larvae per $45 \mathrm{~cm}$ branch tip) above which hotspots begin to emit emigrant moths to surrounding areas [28]. In general, catching hotspots early should reduce the probability of compensation occurring.

Pest reinvasion via dispersal is another compensatory response that can allow populations to rebound even when treatments are highly efficacious (Figure 4). Spruce budworm are prolific dispersers and certain weather conditions can produce long-distance mass-exodus flights that disperse millions of egg-laying or mating moths throughout the region [23]. Although the impact of these mass dispersal events on regional demographic trends remain uncertain, there is clear evidence that moth dispersal from high-density populations (e.g., hotspots) results in successful reproduction [64] and can promote local outbreak spread and reinvasion of treated sites $[6,28,65]$. Compensation through moth reinvasion is a classic problem in pest management and has been one of the major drivers behind the historical use of area-wide management programs [66]. Such regional-scale management programs involve coordinated monitoring and control over large areas as a means of reducing the ability of pests to spread or reinvade treated areas. Commitment and sufficient funding by the participating jurisdictions are necessary for ongoing monitoring and treatments in all or nearly all areas where spruce budworm populations exceed the threshold. Ultimately, whether EIS is successful in Atlantic Canada will depend on whether immigration intensity and frequency from Québec exceeds the capacity to detect and 
control hotspots. After 5 years of trials in northern New Brunswick, however, moth dispersal has so far not thwarted EIS efforts [13].

\subsection{Costs and Benefits}

\subsubsection{Economic}

The economic feasibility of EIS will ultimately depend on how management costs compare with potential losses from an uncontrolled spruce budworm outbreak. Spruce budworm outbreaks cause massive timber supply and economic losses in part because they cover large areas (52 million ha in Canada in 1975; Canadian Council of Forest Ministers 2014) and cause high tree mortality (e.g., > 85\% of balsam fir; [43,67]. Hennigar et al. [68] estimated that an uncontrolled spruce budworm outbreak could reduce future spruce-fir harvests in New Brunswick, from 2013 to 2052, by as much as 18\%-25\%, depending on outbreak severity. In a related study, Chang et al. $[69,70]$ estimated that the associated economic declines (from 2012 to 2041) could be as much as \$3.3-4.7 Billion (CND) depending on the severity of outbreak.

Insect outbreaks can also influence local economies through their impact on non-timber forest products (e.g., Christmas trees, mushrooms, berries, flowers, shrubs), though the economic value of such losses can be harder to quantify (e.g., [71]). Large areas of defoliation and tree mortality can also have impacts on ecotourism and recreation activities such as hiking and camping in provincial and national parks. While all these impacts are dwarfed by the costs of the outbreak to the commercial forestry sector, their mitigation is one of the potential benefits of stopping outbreak spread.

A strong economic case has been made for EIS in New Brunswick and the rest of Atlantic Canada. Using a 50-year timber supply model provided by the Province of New Brunswick, Liu et al. [72] estimated that an uncontrolled outbreak could cause harvest reductions of 29-43 million $\mathrm{m}^{3}$, with associated direct and indirect reductions in economic output of \$25-35 billion. Scenarios of Foliage Protection covering 20\% of susceptible forest area resulted in losses of 6-17 million $\mathrm{m}^{3}$ and \$0.5-4.1 Billion CND. Depending upon outbreak severity, the economic benefits of EIS were 3.8-6.4 times higher than the total potential costs, including the costs of running the program under each scenario [72]. Based on extrapolations of impacts and regional harvest levels, a similar economic case has been made for the rest of Atlantic Canada [13] but whether it applies to other regions within the outbreak range of spruce budworm will require further analyses.

A key difference between EIS and Foliage Protections is the likelihood and magnitude of long-term secondary impacts on forests. Because of budgetary and logistical constraints, Foliage Protection often cannot protect all affected areas and many go untreated, especially during large outbreaks. Thus, even under a perfectly implemented Foliage Protection program, some level of impacts on spruce and fir (i.e., growth loss, mortality) is inevitable. Moreover, severe spruce budworm defoliation on unprotected forests can often invite secondary impacts from bark beetles [73,74], disease [75,76], and forest fire [77-79], which may spill over into adjacent protected stands. For example, out of the 8.2 million ha defoliated to date in Québec [80], budgets have so far only permitted about $250,000-400,000$ ha to be protected each year (i.e., $<5 \%$ of the outbreak area). Ideally, EIS could limit the scale of an outbreak and prevent cumulative defoliation, thereby diminishing risks of secondary mortality factors over large scales.

\subsubsection{Ecological}

Concerns over the ecological costs of insecticide applications that arose in the aftermath of DDT have shaped public perception of pest management, and specifically large-scale insecticide-based spruce budworm management [81,82]. Once an outbreak extends throughout a region, Foliage Protection often necessitated extensive application: at their peak in 1976, insecticide applications in New Brunswick covered over 3.8 million ha [83]. In contrast, through limiting the range of outbreak spread, EIS is expected to substantially limit the scale and duration of annual treatments. In addition to keeping 
defoliation to a minimum, the success of EIS will thus depend on verification of minimal ecological costs-direct and indirect. Efforts to minimize non-target effects have led to the development, regulation and strategic application of narrow-spectrum ingestible insecticides [84], which have been further supported by rigorous research on their toxicology and persistence. Both tebufenozide and $B t k$ have minimal toxicological effects on a wide range of organisms $[9,10]$, apart from larval Lepidopterans (moths and butterflies) that might ingest treated foliage. Even at levels exceeding current application rates, few detectable direct effects of tebufenozide on aquatic taxa have been found $[85,86]$, although potential indirect effects are more nuanced for some groups. For instance, declines in molting and reproduction of midges were not detected in laboratory assays but have been observed under field mesocosm conditions [87]. Reducing these risks involves controlled insecticide application that minimizes drift, buffering around aquatic habitats, and monitoring of insecticide residue and persistence in nearby water bodies. Ongoing research on non-target effects through food webs involving spruce budworm natural enemies is explicitly included in the ongoing EIS project [88].

While the ecological risks associated with EIS treatments are well studied, the flipside- the indirect ecological cost of not intervening against defoliation, and conversely, the ecosystem benefits of outbreak prevention through EIS versus strategies like Foliage Protection-have received little attention. These ecological costs should be highest in stands suffering severe, multi-year defoliation and associated tree mortality, and where salvage logging occurs. EIS aims to avoid this scenario by suppressing pest densities before sustained high defoliation can negatively affect ecosystems. As large-scale disturbances, insect outbreaks can significantly disrupt timber supply but also indirectly affect ecological goods and services provided by forests, including the provision of water resources and flood control, nutrient cycling, and habitat for both terrestrial and aquatic species [89]. Some of these indirect ecological costs translate to direct economic costs, through increased water treatment requirements [90]. Tree mortality and salvage logging following severe defoliation can affect hydrologic regimes and alter soil nutrient cycling, resulting in increased flow and nutrient runoff, and erosion and sedimentation [90-92]. Coupled with these associated hydrologic changes, the loss of streamside canopy cover through defoliation can increase stream temperature, and collectively alter aquatic food webs and in turn, the availability and quality of critical habitat for cold-water fish, including Atlantic Salmon and Brook Trout [91]. Reduced canopy cover and shifts in vegetation may impair habitat for birds, including threatened species (e.g., Canada Warbler) that prey on spruce budworm [93]. Although spruce budworm is a native defoliator with historical periodic impacts on these ecosystems, other ongoing changes and stressors (e.g., commercial logging, climate change, and altered biota) may affect their resilience and functioning in the face of this major disturbance. Because Foliage Protection focuses mainly on economically important forest stands, critical habitats such as those described above typically remain unprotected. In contrast, through limiting the extent of outbreaks, and therefore avoiding significant defoliation, EIS could provide a regional strategy to help maintain the ecological integrity of critical habitats.

\subsubsection{Sociopolitical}

Forest management practices, including EIS, must accommodate differing value systems around the critical roles forests play in cultural and spiritual practices, as well as in human health [94-97]. These sociopolitical dynamics can be difficult to quantify, but are nonetheless a key determinant of whether an EIS program can work. In Foliage Protection these issues tend to be less prominent as the majority of treatments take place on Crown Lands [11]. In contrast, an area-wide management program such as EIS aims to control all areas with hotspots and thus must account for the values of a diverse range of affected stakeholders. In many jurisdictions there are limits to the governing authority to apply treatments onto forests not under their direct control. In New Brunswick, for example, the Crown Lands and Forests Act does not provide the authority to treat federal lands, and allows private landowners to opt-out of the EIS program. Additionally, parks, protected areas, and other conservation zones often have the explicit objective to allow natural processes (including disturbance regimes such as outbreaks 
and forests fires) to unfold without human intervention. Canada has committed to the permanent conservation of $17 \%$ of its terrestrial area by 2020 and the risk that those areas may present a barrier to treatment must be considered when assessing the feasibility of EIS. Although it has not been an issue in the program yet, Provincial and National Park managers may eventually have to weigh potential risks of an outbreak to ecotourism or sensitive habitats against potential impacts on rare species or the natural processes that these areas were set aside to preserve (which may be difficult to know with certainty). Similarly, Indigenous peoples in Canada (e.g., the Mi'gmaw, Wolasoqiyik, Peskotomuhkati in Atlantic Canada, and Innu of Labrador) must be formally consulted if any EIS activities potentially affect Aboriginal or Treaty rights. Thus far, there has been no attempt to implement approaches such as Etuaptmumk ("Two-Eyed Seeing"; [98]) that merge lessons from traditional knowledge with modern science when making management decisions. It remains unclear how much spruce-fir forest might be set aside for exclusions in the future or what effects that might have on the viability of EIS, although it so far has not been a detriment to ongoing experiments [13].

\subsection{Communication and Outreach}

Even if all aspects of EIS work as intended and are highly cost effective, without public support the program could not be sustainable at levels needed for successful regional outbreak control. Controversy has long surrounded insecticide usage for spruce budworm [81,82,99] and concerns linger to this day, despite the replacement of broad-spectrum insecticides with more ecologically benign alternatives. A variety of audiences must be engaged and consulted before treatments can occur, including governmental decision-makers, industry, environmental groups, Indigenous Peoples, landowner organizations, provincial and federal parks, municipalities, provincial and local media, and residents. A core component of EIS is a proactive (and bilingual) communications approach that improves knowledgeability about EIS science and management, spruce budworm ecology, and the tactics used in the past and present. This proactive approach contrasts the more reactive approach that has underpinned most past Foliage Protection operations [99]. In Atlantic Canada, a consortium of scientists, government, industry, landowner organizations, and communications experts from throughout the region (i.e., the Health Forest Partnership [100]) meets regularly to discuss and oversee the EIS communications strategy.

\subsubsection{Communications Strategy}

A few core principles guide the approach. First, scientists and other experts are the communications ambassadors for EIS management and science. This approach gives audiences opportunities to engage with experts directly and reduces the likelihood of miscommunications around the underlying science or ongoing management efforts. Second, timely updates are communicated on all aspects of EIS, including on spruce budworm population trends, location and timing of treatments, and the ongoing progress in the management and scientific research. Finally, scientists and other experts address all public inquiries and concerns directly and openly, and where possible provide reference material from available scientific literature.

\subsubsection{Key Messages}

Several key messages have become central to EIS communications, in part because they reflect the most frequently asked questions.

Public presentations by scientists and other experts emphasize the important ecological role spruce budworm plays in forest ecology and succession and highlight the historical record of outbreaks as a natural disturbance in our forests since at least the Holocene [101]. This context helps to convey the message that the aim of EIS is not spruce budworm eradication, but rather control of populations to limit the scale and magnitude of the regional impacts. As we often state in public forums, we are in effect playing a game of hotspot "whack-a-mole" in northern New Brunswick with the expectation that it saves us from having to control spruce budworm to the south. 
Concerns around the possible environmental and health impacts of insecticides are the most common and persistent issue raised. A significant portion of EIS outreach therefore focuses on explaining past and present insecticide usage, including details on biological modes of action, environmental persistence, and potential non-target impacts of the two narrow-spectrum insecticides employed in EIS. The messages emphasize that the insecticides need only add a small amount of mortality to that occurring naturally to be effective. By aggressively targeting hotspots where they arise near the ongoing outbreak, EIS may prevent outbreaks in the rest of Atlantic Canada.

For groups or managers considering whether to authorize EIS on their lands (e.g., First Nations Lands, Federal and Provincial Parks, Protected Natural Areas), communications efforts focus on explaining the details of the program and establishing collaborations for spruce budworm monitoring. The goal is not to convince such groups to participate in EIS, but rather to provide the tools, data, and information needed to foster productive conversations and support informed decisions once hotspots appear.

\subsubsection{Outreach Tactics}

EIS communications uses a variety of tools and approaches for dissemination of information and outreach. These include direct engagement through scientific talks, lectures, meetings, exhibits, and roundtables. Information is also made available through an active website [100] with written and video Blogs, informative videos, infographics, and live updates, as well as through proactive media engagement. Scientists typically address questions during talks, panel discussions, and forums, but are also accessible through direct e-mails, phone calls, or by submitting questions through the website. One particularly effective outreach tool has been a Budworm Tracker community science program, which serves the dual purposes of providing data on regional moth density and dispersal, as well as community engagement [102].

In terms of the efficacy of this approach, since 2015 there have been $>165$ individual stories published $>300$ times about EIS in various local and national media outlets. Coverage to date has been universally positive. Moreover, of the $\sim 3175$ private landowners that have been given the option to opt out of EIS treatments in New Brunswick, $<4 \%$ have done so.

\section{Conclusions}

Our EIS framework illustrates the fundamental components of managing spruce budworm through a proactive population control strategy (Figure 1). This framework offers a roadmap to jurisdictions considering proactive EIS vs. reactive Foliage Protection for spruce budworm. These strategies are not necessarily mutually exclusive and there may be areas or conditions where one strategy is more viable than the other. Although the details of this framework are built around stopping spruce budworm outbreaks, its core elements are relevant to population control for insect pests that show a hotspot-style outbreak dynamic. This might include other species of outbreak-prone budworm species (e.g., Choristoneura sp. and Acleris sp.), though the extent to which these systems fit within our EIS framework remains uncertain.

While this framework has to date proven highly effective for controlling outbreak spread [13], there remain areas of uncertainty and opportunity that warrant further investigation. There is already evidence for climate change induced shifts in the spruce budworm outbreak range and dynamics [103-105]. While these are not likely relevant to the current ongoing outbreak, future range shifts could have significant implications for where EIS might be most efficacious. Moreover, any innovation that improves our fundamental understanding or the efficacy of tools and practices in the EIS framework are likely to increase its viability. This could include the development of more efficient hotspot monitoring and detection protocols, new or additional tactics for population control, or new economic markets or disturbances that further enhance the cost-benefit case for using EIS. Another area of uncertainty is that the proposed EIS framework assumes an absence of genetic barriers to spruce budworm dispersal or establishment. Also unknown is the role of spatial adaptive 
genetic variation in spruce budworm, including variation in voltinism, genomic legacies of post-glacial expansion, or trade-offs between different host trees. Although these are interesting and promising areas of active research, given the regional (vs. continental) scale at which EIS is likely to be applied we would not expect such variation to be a major hindrance to an EIS program.

Aside from its pest management implications, the EIS is also a rare test of applied population theory. Population dynamics sits at the core of EIS and decades of research (and debate) have revealed an eruptive-spread dynamic that should be conducive to EIS. Attempting to manage outbreaks through an EIS also constitutes a test of predictions emanating from the double-equilibrium versus oscillatory hypotheses at very large scales. In particular, EIS tests predictions underlying cyclic vs. irruptive-collapse dynamics and the extent to which outbreaks reflect range-wide processes vs. local irruptions with contagious spread. It is worth acknowledging that these "experiments" lack true replication or experimental controls, i.e., there are not multiple New Brunswicks available that can be randomly assigned to treatments and controls. On the other hand, large-scale studies such as EIS may offer more realistic results than might arise from small but well-replicated mesocosm experiments [106]. EIS offers a unique opportunity to improve our fundamental understanding of spruce budworm spatiotemporal dynamics and to what extent intervention can alter those dynamics for better management outcomes.

Supplementary Materials: The following are available online at http://www.mdpi.com/1999-4907/10/10/910/s1, Table S1: Patterns and causes of periodic outbreaks, according to two contrasting theories, and how to optimally manage populations under each set of assumptions.

Author Contributions: Conceptualization, R.C.J., V.M., D.A.M., D.S.P. and J.R.; Writing—original draft preparation, R.C.J. and D.T.Q. with significant contributions for individual sections by R.C.J., J.J.B., D.R.C., B.J.C., S.E., E.J.S.E., P.M.A.J., D.K., D.A.M., V.M., E.R.D.M., G.D.M., C.J.N., E.O., D.S.P., D.T.Q., J.R., B.R. and M.S.; Writing-review and editing, all authors; Visualization, R.C.J., S.E., J.R. and B.J.C.; Funding acquisition, R.C.J., J.J.B., B.J.C., V.M., D.A.M., E.J.S.E., D.S.P., J.R. and M.S.

Funding: This research was funded by Atlantic Canada Opportunities Agency, Natural Resources Canada, Government of New Brunswick, and forest industry in New Brunswick.

Acknowledgments: We are also grateful to S. Butterson and B. Pike and two anonymous reviewers for constructive comments on earlier versions of this manuscript. The EIS research was overseen by the Healthy Forest Partnership, a consortium of researchers, landowners, forestry companies, governments, and forest protection experts. Many scientists and staff of industry and government agencies have made important contributions without which the project could not have proceeded.

Conflicts of Interest: The authors declare no conflict of interest.

\section{References}

1. Risser, P.G. Landscape ecology: State of the art. In Landscape Heterogeneity and Disturbance; Turner, M.G., Ed.; Springer: New York, NY, USA, 1987; pp. 3-14.

2. Sturtevant, B.R.; Cooke, B.J.; Kneeshaw, D.D.; MacLean, D.A. Modelling insect disturbance across forested landscapes: Insights from spruce budworm. In Simulation Modelling of Forest Landscape Disturbances; Perera, A.H., Sturtevant, B.R., Buse, L.J., Eds.; Springer International Publishing: Geneva, Switzerland, 2015; pp. 93-134.

3. Pureswaran, D.; Johns, R.C.; Heard, S.B.; Quiring, D. Paradigms in eastern spruce budworm (Lepidoptera: Tortricidae) population ecology: A century of debate. Environ. Entomol. 2016, 45, 1333-1342. [CrossRef] [PubMed]

4. Webb, F.E. Studies of Aerial Spraying Against the Spruce Budworm in New Brunswick: A Preliminary Report on the 1952 Upsalquitch Project; Interim Report; Forest Biology Laboratory: Fredericton, NB, Canada, 1952; pp. 1-9.

5. Kettela, E.G. Aerial spraying for protection of forests infested by spruce budworm. For. Chron. 1975, 51, 141-142. [CrossRef]

6. MacDonald, D.R.; Webb, F.E. Insecticides and the spruce budworm. Mem. Entomol. Soc. Can. 1963, 95, 288-310. [CrossRef]

7. Randall, A.P. Evidence of DDT resistance in populations of spruce budworm, Choristoneura fumiferana (Clem.), from DDT-sprayed areas of New Brunswick. Can. Entomol. 1965, 97, 1281-1293. [CrossRef] 
8. Van Frankenhuyzen, K. Development and current status of Bacillus thuringiensis for control of defoliating forest insects. In Forest Insect Pests in Canada; Armstrong, J.A., Ives, W.G.H., Eds.; Canadian Forest Service: Ottawa, ON, Canada, 1995; pp. 315-325.

9. Durkin, P. Control/Eradication Agents for the Gypsy Moth: Human Health and Ecological Risk Assessment for Bacillus thuringiensis var. Kurstaki (B.T.K.); Syracuse Environment Research Associates, Inc.: Fayetteville, NY, USA, 2004; p. 152.

10. Durkin, P.; Klotzbach, J. Control/Eradication Agents for the Gypsy Moth - Human Health and Ecological Risk Assessment for Tebufenozide (Mimic); Syracuse Environment Research Associates, Inc.: Fayetteville, NY, USA, 2004; p. 161.

11. Fuentealba, A.; Dupont, A.; Hébert, C.; Berthiaume, R.; Quezada-García, R.; Bauce, É. Comparing the efficacy of various aerial spraying scenarios using Bacillus thuringiensis to protect trees from spruce budworm defoliation. For. Ecol. Manag. 2019, 432, 1013-1021. [CrossRef]

12. Ministère des Forêts, de la Faune et des Parcs. Aires Infestées par la Tordeuse des Bourgeons de L'épinette au Québec en 2015-Version 1.0; Gouvernement du Québec, Direction de la Protection des Forêts: Quebec, QC, Canada, 2015.

13. MacLean, D.A.; Amirault, P.; Amos-Binks, L.; Carleton, D.; Hennigar, C.; Johns, R.C.; Régnière, J. Positive results of an Early Intervention Strategy to suppress a spruce budworm outbreak after five years. Forests 2019, 10, 448. [CrossRef]

14. Sharov, A.A.; Leonard, D.; Liebhold, A.M.; Roberts, E.A.; Dickerson, W. "Slow the spread": A national program to contain the gypsy moth. J. For. 2002, 100, 30-36.

15. Bomford, M.; O’Brien, P. Eradication or control for vertebrate pests? Wildl. Soc. Bull. 1995, 23, $249-255$.

16. Sandercock, B.K.; Nilsen, E.B.; Brøseth, H.; Pedersen, H.C. Is hunting mortality additive or compensatory to natural mortality? Effects of experimental harvest on the survival and cause-specific mortality of willow ptarmigan. J. Anim. Ecol. 2011, 80, 244-258. [CrossRef]

17. Royama, T. Population dynamics of the spruce budworm Choristoneura fumiferana. Ecol. Monogr. 1984, 54, 429-462. [CrossRef]

18. Royama, T.; Eveleigh, E.S.; Morin, J.R.B.; Pollock, S.J.; McCarthy, P.C.; McDougall, G.A.; Lucarotti, C.J. Mechanisms underlying spruce budworm outbreak processes as elucidated by a 14-year study in New Brunswick, Canada. Ecol. Monogr. 2017, 87, 600-631. [CrossRef]

19. Régnière, J.; Lysyk, T.J. Population dynamics of the spruce budworm, Choristoneura fumiferana. In Forest Insects Pests in Canada; Armstrong, J.A., Ives, W.G.H., Eds.; Natural Resources Canada, Canadian Forest Service Publication: Ottawa, ON, Canada, 1995; pp. 95-105.

20. Williams, D.W.; Liebhold, A.M. Spatial synchrony of spruce budworm outbreaks in eastern North America. Ecology 2000, 81, 2753-2766. [CrossRef]

21. Royama, T.; MacKinnon, W.E.; Kettela, E.G.; Carter, N.E.; Hartling, L.K. Analysis of spruce budworm outbreak cycles in New Brunswick, Canada, since 1952. Ecology 2005, 86, 1212-1224. [CrossRef]

22. Greenbank, D.O. The role of climate and dispersal in the initiation of outbreaks of the spruce budworm in New Brunswick. I. The role of climate. Can. J. Zool. 1956, 34, 453-476. [CrossRef]

23. Boulanger, Y.; Fabry, F.; Kilambi, A.; Pureswaran, D.S.; Sturtevant, B.R.; Saint-Amant, R. The use of weather surveillance radar and high-resolution three dimensional weather data to monitor a spruce budworm mass exodus flight. Agric. Forest Meteorol. 2017, 234, 127-135. [CrossRef]

24. Régnière, J.; Nealis, V.G. Density dependence of egg recruitment and moth dispersal in spruce budworms. Forests 2019, 10, 706. [CrossRef]

25. Cooke, B.J.; Nealis, V.G.; Régnière, J. Insect defoliators as periodic disturbances in northern forest ecosystems. In Plant Disturbance Ecology: The Process and the Response; Johnson, E.A., Miyanishi, K., Eds.; Elsevier Academic Press: Burlington, MA, USA, 2007; pp. 487-526.

26. Morris, R.F. The dynamics of epidemic spruce budworm populations. Mem. Entomol. Soc. Can. 1963, 95, 7-12. [CrossRef]

27. Ludwig, D.; Jones, D.D.; Holling, C.S. Qualitative analysis of insect outbreak systems: The spruce budworm and forest. J. Anim. Ecol. 1978, 47, 315-332. [CrossRef]

28. Régnière, J.; Cooke, B.J.; Béchard, A.; Dupont, A.; Therrien, P. Dynamics and management of rising outbreak spruce budworm populations. Forests 2019, 10, 748. [CrossRef] 
29. Bouchard, M.; Régnière, J.; Therrien, P. Bottom-up factors contribute to large-scale synchrony in spruce budworm populations. Can. J. For. Res. 2018, 48, 277-284. [CrossRef]

30. Régnière, J.; Delisle, J.; Pureswaran, D.; Trudel, R. Mate-finding Allee effect in spruce budworm population dynamics. Entomol. Exp. Appl. 2013, 146, 112-122. [CrossRef]

31. Régnière, J.; Nealis, V.G. Ecological mechanisms of population change during outbreaks of the spruce budworm. Ecol. Entomol. 2007, 32, 461-477. [CrossRef]

32. Liebhold, A.; Bascompte, J. The Allee effect, stochastic dynamics and the eradication of alien species. Ecol. Lett. 2003, 6, 133-140. [CrossRef]

33. Cappuccino, N.; Lavertu, D.; Bergeron, Y.; Régnière, J. Spruce budworm impact, abundance and parasitism rate in a patchy landscape. Oecologia 1998, 114, 236-242. [CrossRef] [PubMed]

34. Eveleigh, E.S.; McCann, K.S.; McCarthy, P.C.; Pollock, S.J.; Lucarotti, C.J.; Morin, B.; McDougall, G.A.; Strongman, D.B.; Huber, J.T.; Umbanhowar, J.; et al. Fluctuations in density of an outbreak species drive diversity cascades in food webs. Proc. Natl. Acad. Sci. USA 2007, 104, 16976-16981. [CrossRef]

35. Marrec, R.; Pontbriand-Paré, O.; Legault, S.; James, P.M.A. Spatiotemporal variation in drivers of parasitoid metacommunity structure in continuous forest landscapes. Ecosphere 2018, 9, e02075. [CrossRef]

36. Legault, S.; James, P.M.A. Parasitism rates of spruce budworm larvae: Testing the enemy hypothesis along a gradient of forest diversity measured at different spatial scales. Environ. Entomol. 2018, 47, 1083-1095. [CrossRef]

37. Miller, C.A.; Kettela, E.G.; McDougall, G.A. A Sampling Technique for Overwintering Spruce Budworm and Its Applicability to Population Surveys; Canadian Forestry Service: Fredericton, NB, Canada, 1971; p. 11.

38. Sanders, C.J. Monitoring spruce budworm population density with sex pheromone traps. Can. Entomol. 1988, 120, 175-183. [CrossRef]

39. MacLean, D.A.; MacKinnon, W.E. Accuracy of aerial sketch-mapping of spruce budworm defoliation in New Brunswick. Can. J. For. Res. 1996, 26, 2099-2108. [CrossRef]

40. Régnière, J.; Delisle, J.; Sturtevant, B.; Garcia, M.; St-Amant, R. Modeling migratory flight in the spruce budworm: Temperature Constraints. Forests 2019, 10, 802. [CrossRef]

41. Rahimzadeh-Bajgiran, P.; Weiskittel, A.; Kneeshaw, D.; MacLean, D.A. Detection of annual spruce budworm defoliation and severity classification using Landsat imagery. Forests 2018, 9, 357. [CrossRef]

42. Goodbody, T.R.H.; Coops, N.C.; Hermosilla, T.; Tompalski, P.; McCartney, G.; MacLean, D.A. Digital aerial photogrammetry for assessing cumulative spruce budworm defoliation and enhancing forest inventories at a landscape-level. ISPRS J. Photogramm. Remote Sens. 2018, 142, 1-11. [CrossRef]

43. MacLean, D.A. Vulnerability of fir-spruce stands during uncontrolled spruce budworm outbreaks: A review and discussion. For. Chron. 1980, 56, 213-221. [CrossRef]

44. Hennigar, C.R.; MacLean, D.A.; Quiring, D.T.; Kershaw, J.A. Differences in spruce budworm defoliation among balsam fir and white, red, and black spruce. For. Sci. 2008, 54, 158-166.

45. Bognounou, F.; De Grandpré, L.; Pureswaran, D.S.; Kneeshaw, D. Temporal variation in plant neighborhood effects on the defoliation of primary and secondary hosts by an insect pest. Ecosphere 2017, 8, e01759. [CrossRef]

46. Su, Q.; Needham, T.D.; MacLean, D.A. The influence of hardwood content on balsam fir defoliation by spruce budworm. Can. J. For. Res. 1996, 26, 1620-1628. [CrossRef]

47. Campbell, E.M.; MacLean, D.A.; Bergeron, Y. The severity of budworm-caused growth reductions in balsam fir/spruce stands varies with the hardwood content of surrounding forest landscapes. For. Sci. 2008, 54, 195-205.

48. Zhang, B.; MacLean, D.A.; Johns, R.C.; Eveleigh, E.S. Effects of hardwood content on balsam fir defoliation during the building phase of a spruce budworm outbreak. Forests 2018, 9, 530. [CrossRef]

49. Robert, L.E.; Kneeshaw, D.; Sturtevant, B.R. Effects of forest management legacies on spruce budworm (Choristoneura fumiferana) outbreaks. Can. J. For. Res. 2012, 42, 463-475. [CrossRef]

50. Robert, L.E.; Sturtevant, B.R.; Cooke, B.J.; James, P.M.; Fortin, M.J.; Townsend, P.A.; Wolter, P.T.; Kneeshaw, D. Landscape host abundance and configuration regulate periodic outbreak behavior in spruce budworm Choristoneura fumiferana. Ecography 2018, 41, 1556-1571. [CrossRef]

51. Bouchard, M.; Auger, I. Influence of environmental factors and spatio-temporal covariates during the initial development of a spruce budworm outbreak. Landsc. Ecol. 2014, 29, 111-126. [CrossRef] 
52. Bauce, É.; Carisey, N.; Dupont, A.; van Frankenhuyzen, K. Bacillus thuringiensis subsp. kurstaki aerial Spray prescriptions for balsam fir stand protection against spruce budworm (Lepidoptera: Tortricidae). J. Econ. Entomol. 2004, 97, 97-1624. [CrossRef] [PubMed]

53. van Frankenhuyzen, K.; Régnière, J. Multiple effects of tebufenozide on the survival and performance of the spruce budworm (Lepidoptera: Tortricidae). Can. Entomol. 2017, 149, 227-240. [CrossRef]

54. Régnière, J.; Delisle, J.; Dupont, A.; Trudel, R. The impact of moth migration on apparent fecundity overwhelms mating disruption as a method to manage spruce budworm populations. Forests 2019, 10, 775. [CrossRef]

55. Rhainds, M.; Kettela, E.G.; Silk, P.J. Thirty-five years of pheromone-based mating disruption studies with Choristoneura fumiferana (Clemens) (Lepidoptera: Tortricidae). Can. Entomol. 2012, 144, 379-395. [CrossRef]

56. Crawford, H.S.; Titterington, R.W.; Jennings, D.T. Bird predation and spruce budworm populations. J. For. 1983, 81, 433-478.

57. Jennings, D.T.; Houseweart, M.W. Predation by eumenid wasps (Hymenoptera: Eumenidae) on spruce budworm (Lepidoptera: Tortricidae) and other lepidopterous larvae in spruce-fir forests of Maine. Ann. Entomol. Soc. Am. 1984, 77, 39-45. [CrossRef]

58. Waage, J.K.; Hassell, M.P.; Godfray, H.C.J. The dynamics of pest-parasitoid-insecticide interactions. J. Appl. Ecol. 1985, 22, 825-838. [CrossRef]

59. Nealis, V.; van Frankenhuyzen, K. Interactions between Bacillus thuringiensis Berliner and Apanteles fumiferanae Vier. (Hymenoptera: Braconidae), a parasitoid of the spruce budworm, Choristoneura fumiferana (Clem.) (Lepidoptera: Tortricidae). Can. Entomol. 1990, 122, 585-594. [CrossRef]

60. Nealis, V.; van Frankenhuyzen, K.; Cadogan, B.L. Conservation of spruce budworm parasitoids following application of Bacillus thuringiensis var. kurstaki Berliner. Can. Entomol. 1992, 124, 1085-1092. [CrossRef]

61. Cooke, B.J.; Régnière, J. An objectoriented, process-based stochastic simulation model of Bacillus thuringiensis efficacy against spruce budworm, Choristoneura fumiferana (Lepidoptera: Tortricidae). Int. J. Pest Manag. 1996, 42, 291-306. [CrossRef]

62. Quiring, D.; Flaherty, L.; Adams, G.; McCartney, A.; Miller, J.D.; Edwards, S. An endophytic fungus interacts with crown level and larval density to reduce the survival of eastern spruce budworm, Choristoneura fumiferana (Lepidoptera: Tortricidae), on white spruce (Picea glauca). Can. J. For. Res. 2019, 49, 221-227. [CrossRef]

63. Williams, M.; Eveleigh, E.; Forbes, G.; Lamb, R.; Roscoe, L.; Silk, P. Evidence of a direct chemical plant defense role for maltol against spruce budworm. Entomol. Exp. Appl. 2019, 167, 755-762. [CrossRef]

64. Larroque, J.; Legault, S.; Johns, R.; Lumley, L.; Cusson, M.; Renaut, S.; Levesque, R.C.; James, P.M.A. Temporal variation in spatial genetic structure during population outbreaks: Distinguishing among different potential drivers of spatial synchrony. Evol. Appl. 2019. [CrossRef]

65. Dobesberger, E.J.; Lim, K.P.; Raske, A.G. Spruce budworm (Lepidoptera: Tortricidae) moth flight from New Brunswick to Newfoundland. Can. Entomol. 1983, 115, 1641-1645. [CrossRef]

66. Elliott, N.C.; Onstad, D.W.; Brewer, M.J. History and ecological basis for areawide pest management. In Area-wide Pest Management: Theory and Implementation; Koul, O., Cuperus, G.W., Elliott, N., Eds.; CABI International: Oxford, UK, 2008; pp. 15-33.

67. MacLean, D.A.; Ostaff, D.P. Patterns of balsam fir mortality caused by an uncontrolled spruce budworm outbreak. Can. J. Forest Res. 1989, 19, 1087-1095. [CrossRef]

68. Hennigar, C.R.; Erdle, T.A.; Gullison, J.J.; MacLean, D.A. Re-examining wood supply in light of future spruce budworm outbreaks: A case study in New Brunswick. For. Chron. 2013, 89, 42-53. [CrossRef]

69. Chang, W.Y.; Lantz, V.A.; Hennigar, C.R.; MacLean, D.A. Benefit-cost analysis of spruce budworm (Choristoneura fumiferana Clem.) control: Incorporating market and non-market values. J. Environ. Manag. 2012, 93, 104-112. [CrossRef]

70. Chang, W.Y.; Lantz, V.A.; Hennigar, C.R.; MacLean, D.A. Economic impacts of spruce budworm (Choristoneura fumiferana Clem.) outbreaks and control in New Brunswick, Canada. Can. J. For. Res. 2012, 42, 490-505. [CrossRef]

71. Cathro, J.; Mulkey, S.; Bradley, T. A bird's eye view of small tenure holdings in British Columbia. J. Ecosyst. Manag. 2007, 8, 58-66.

72. Liu, E.Y.; Lantz, V.; MacLean, D.A.; Hennigar, C. Economics of early intervention to suppress a potential spruce budworm outbreak on Crown land in New Brunswick, Canada. Forests 2019, 10, 481. [CrossRef] 
73. Belyea, R.M. Death and deterioration of balsam fir weakened by spruce budworm defoliation in Ontario. Can. Entomol. 1952, 84, 325-335. [CrossRef]

74. Ostaff, D.P.; MacLean, D.A. Spruce budworm populations, defoliation, and changes in stand condition during an uncontrolled spruce budworm outbreak on Cape Breton Island, Nova Scotia. Can. J. For. Res. 1989, 19, 1077-1086. [CrossRef]

75. Stillwell, M.A. Pathological aspects of severe spruce budworm attack. For. Sci. 1956, 2, 174-180.

76. Ostaff, D. D. A Wood Quality Study of Dead and Dying Balsam Fir-The Incidence of Armillaria Root Rot; Technical Note 82; Environment Canada, Canadian Forestry Service, Maritimes Forest Research Centre: Fredericton, NB, Canada, 1983.

77. Stocks, B.J. Fire potential in the spruce budworm-damaged forests of Ontario. For. Chron. 1987, 63, 8-14. [CrossRef]

78. James, P.M.A.; Fortin, M.J.; Sturtevant, B.R.; Fall, A.; Kneeshaw, D. Modelling spatial interactions among fire, spruce budworm, and logging in the boreal forest. Ecosystems 2011, 14, 60-75. [CrossRef]

79. James, P.M.A.; Robert, L.E.; Wotton, B.M.; Martell, D.L.; Fleming, R.A. Lagged cumulative spruce budworm defoliation affects the risk of fire ignition in Ontario, Canada. Ecol. Appl. 2017, 27, 532-544. [CrossRef]

80. QMFFP: Québec Ministère des Forêts, de la Faune et des Parcs. Aires Infestées par la Tordeuse des Bourgeons de L'épinette au Québec en 2018; Gouvernement du Québec, Direction de la Protection des Forêts: Québec City, QC, Canada, 2018; p. 20.

81. Carson, R. Silent Spring; Houghton Mifflin: New York, NY, USA, 1962.

82. May, E. Budworm Battles; Four East Publications Ltd.: Halifax, NS, Canada, 1982.

83. Armstrong, J.A.; Cook, C.A. Aerial Spray Applications on Canadian Forests: 1945-1990; Information Report; Forestry Canada: Ottawa, ON, Canada, 1993.

84. Holmes, S.B.; MacQuarrie, C.J.K. Chemical control in forest pest management. Can. Entomol. 2016, 148, S270-S295. [CrossRef]

85. Soin, T.; Smagghe, G. Endocrine disruption in aquatic insects: A review. Ecotoxicology 2007, 16, 83-93. [CrossRef]

86. Kreutzweiser, D.P.; Gunn, J.M.; Thompson, D.G.; Pollard, H.G.; Faber, M.J. Zooplankton community responses to a novel forest insecticide, tebufenozide (RH-5992), in littoral lake enclosures. Can. J. Fish. Aquat. Sci. 1998, 55, 639-648. [CrossRef]

87. Tassou, K.T.; Schulz, R. Low filed-relevant tebufenozide concentrations affect reproductions in Chironomus riparius (Diptera: Chironomidae) in a long-term toxicity test. Environ. Sci. Pollut. Res. 2013, 20, 3735-3742. [CrossRef] [PubMed]

88. Martel, V.; Johns, R.C.; Eveleigh, E.; McCann, K.; Pureswaran, D.; Sylvain, Z.; Morrison, A.; Morin, B.; Owens, E.; Hébert, C. Landscape level impacts of EIS on SBW, other herbivores and associated natural enemies (ACOA RD100 2.2.2). In Proceedings of the SERG-I Workshop, Fredericton, NB, Canada, 7-8 February 2017; pp. 112-118.

89. Schowalter, T.D. Insect herbivore effects on forest ecosystem services. J. Sustain. For. 2012, 31, 518-536. [CrossRef]

90. Postel, S.L.; Thompson, B.H., Jr. Watershed protection: Capturing the benefits of nature's water supply services. Nat. Resour. Forum 2005, 29, 98-108. [CrossRef]

91. Dhar, A.; Parrott, L.; Heckbert, S. Consequences of mountain pine beetle outbreak on forest ecosystem services in western Canada. Can. J. For. Res. 2016, 46, 987-999. [CrossRef]

92. Redding, T.; Winkler, R.; Teti, P.; Spittlehouse, D.; Boon, S.; Rex, J.; Dubé, S.; Moore, R.D.; Wei, A.; Carver, M.; et al. Mountain pine beetle and watershed hydrology. BCJ. Ecosys. Manag. 2008, 9, 33-50.

93. Venier, L.A.; Holmes, S.B. A review of the interaction between forest birds and eastern spruce budworm. Environ. Rev. 2010, 18, 191-207. [CrossRef]

94. Crewe, J.; Johnstone, J.F. Plant Use in Vuntut Gwitchin Territory; Vuntut Gwitchin First Nation: Old Crow, YT, Canada, 2008; pp. 1-49.

95. Kanowski, P.J.; Williams, K.J.H. The reality of imagination: Integrating the material and cultural values of old forests. For. Ecol. Manag. 2009, 258, 341-346. [CrossRef]

96. Nowak, D.J.; Hirabayashi, S.; Bodine, A.; Greenfield, E. Tree and forest effects on air quality and human health in the United States. Environ. Pollut. 2014, 193, 119-129. [CrossRef] 
97. Chang, W.Y.; Lantz, V.A.; MacLean, D.A. Public attitudes about forest pest outbreaks and control: Case studies in two Canadian provinces. For. Ecol. Manag. 2009, 257, 1333-1343. [CrossRef]

98. Two-Eyed Seeing. Available online: http://www.integrativescience.ca/Principles/TwoEyedSeeing/ (accessed on 12 August 2019).

99. Miller, A. Conventional problem solving. In Environmental Problem Solving: Psychosocial Barriers to Adaptive Change, 1st ed.; Alexander, D.E., Ed.; Springer: New York, NY, USA, 1999; pp. 82-123.

100. Healthy Forest Partnership. Available online: http://www.healthyforestpartnership.ca (accessed on 12 August 2019).

101. Simard, I.; Morin, H.; Lavoie, C. A millennial-scale reconstruction of spruce budworm abundance in Saguenay, Quebec, Canada. Holocene 2006, 16, 31-37. [CrossRef]

102. Budworm Tracker Program. Available online: http://healthyforestpartnership.ca/budworm-tracker/aboutthe-program/ (accessed on 23 September 2019).

103. Régnière, J.; St-Amant, R.; Duval, P. Predicting insect distributions under climate change from physiological responses: Spruce budworm as an example. Biol. Invasions 2012, 14, 1571-1586. [CrossRef]

104. Pureswaran, D.S.; De Grandpré, L.; Paré, D.; Taylor, A.; Barrette, M.; Morin, H.; Régnière, J.; Kneeshaw, D. Climate-induced changes in host tree-insect phenology may drive ecological state-shift in boreal forests. Ecology 2015, 96, 1480-1491. [CrossRef]

105. Pureswaran, D.S.; Neau, M.; Marchand, M.; De Grandpré, L.; Kneeshaw, D. Phenological synchrony between eastern spruce budworm and its host trees increases with warmer temperatures in the boreal forest. Ecol. Evol. 2018, 9, 576-586.

106. Schindler, D.W. Replication versus realism: The need for ecosystem-scale experiments. Ecosystems 1998, 1, 323-334. [CrossRef]

(C) 2019 by the authors. Licensee MDPI, Basel, Switzerland. This article is an open access article distributed under the terms and conditions of the Creative Commons Attribution (CC BY) license (http://creativecommons.org/licenses/by/4.0/). 